This journal is the official publication of Bangladesh Society of Physiologists (BSP)

Web URL: www.banglajol.info/index.php/JBSP

Abstracted /indexed in Index Copernicus, Director of Open Access Journal, Index Medicus for South East Asia Region, Google Scholar, 12OR, infobse index, Open J gate, Cite factor, Scientific indexing services

pISSN-1983-1213; e-ISSN-2219-7508

Article

Article information:

Received on March 2019

Accepted on June 2019

DOI: https://doi.org/10.3329/jbsp.v14i1.41995

Corresponding author:

Shams Ruhani Islam, Dept. of Physiology, Suhrawardy Medical College, Dhaka.

E-mail: shams.ruhani@yahoo.com

Cite this article:

Islam SR, Ferdousi S. Music therapy on non linear assessment of cardiac autonomic function in patients with major depressive disorder

J Bangladesh Soc Physiol 2019;14(1): 7-13

This article is open access licensed under CC BY NC SA which allows readers copy, distribute, display, and perform the work and make derivative works based on it only for noncommercial purposes.

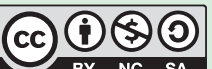

\section{Music therapy on non linear assessment of cardiac autonomic function in patients with major depressive disorder}

\author{
Shams Ruhani Islam ${ }^{1}$, Sultana Ferdousi ${ }^{2}$ \\ 1. Department of Physiology, Suhrawardy Medical College, Dhaka. \\ 2. Department of Physiology, BSMMU, Dhaka.
}

\section{Abstract}

Background :Non linear measure of heart rate variability (HRV) is an emerging method to detect changes in cardiac autonomic nerve function in major depressive disorder (MDD). Objective: To observe the effect of music therapy on non linear measures of HRV in newly diagnosed MDD patients. Methods: This prospective interventional study was done in the Department of Physiology, Bangabandhu Sheikh Mujib Medical University (BSMMU), Shahbag, Dhaka in 2018 on 60 newly diagnosed MDD patients aged 20-40 years, both male and female. They were further subdivided into 30 patients with only antidepressant medication (Mirtazapine) and 30 patients received music therapy with Raga kafi (Rabindrasangeet) along with the same medication for 3 months. Age, sex and BMI matched healthy control were also enrolled. HRV non linear parameters were recorded by Power Lab $8 / 35$. For statistical analysis paired sample ' $t$ ' test and independent sample ' $t$ ' test were done. Result: SD1, SD2 and SD1/SD2 were found significantly lower in MDD patients compared to healthy control at baseline. After 3 months of music therapy, significant increment of these parameters occurred with trend of improvement in cardiac autonomic nerve function (CANF) in these patients. Conclusion: This study concluded that music therapy can improve CANF by increasing parasympathetic and reducing sympathetic activity in MDD patients.

Keywords: Music, $\mathrm{SD}, \mathrm{SD}_{2}$, MDD. 
Introduction

D epression is a common mental health problem affecting 322 million people worldwide. About $4.1 \%$ of Bangladeshi people suffers from depression ${ }^{1}$. Major depressive disorder (MDD) is a subclass of depressive disorder, essentially featured in DSM$\mathrm{V}$ as depressed mood or loss of interest or pleasure in nearly all activities for at least two weeks $^{2}$.

MDD is closely associated with cardiovascular health. Research evidence showed 2-4 fold higher risk of cardiac mortality in depressed patients compared to healthy individuals ${ }^{3}$. They are also prone to suffer from coronary artery disease, myocardial infarction, hypertension and cardiac failure ${ }^{4}$. MDD has been appeared to have an impact on autonomic modulation of heart $5^{5-8}$.

$\mathrm{HRV}$ is a convenient noninvasive measurement of beat to beat changes in heart rate which expresses the output of CANF from central autonomic modulation ${ }^{9}$. Nonlinear methods represents potentially effective tool for HRV assessment but standards are lacking and full scope of these methods can't be determined ${ }^{10}$.

Most common nonlinear method is Poincare plot, which is a geometrical representation that permits the visual identification of the presence of non linear HRV. The Poincare plot is quantified by measuring SD1, SD2 and SD1/SD2 components. SD1 is the standard deviation of the Poincare plot (PP) perpendicular to the line of identity and it measures short term variability representing parasympathetic tone. SD2 is the standard deviation of the PP along the line of identity and measures long term HRV indicating sympathetic status. SD1/SD2 reflects proportion of short term and long term variability and evaluates sympathovagal balance ${ }^{11-13}$.

Major depression has been shown to have a detectable influence on autonomic modulation of heart ${ }^{7,8}$. Though music have therapeutic effect in preoperative patients, cancer patients and in metabolic syndrome ${ }^{14-16}$, but very few studies investigated effects of music therapy on depression. Music has a beneficial role when combined with standard care ${ }^{17-19}$.

Though music therapy has been successful for reducing symptoms of depression but no published report on investigating the effect of music therapy on nonlinear measures of HRV in depression is available. Therefore this study aimed to investigate the effect of music on CANF by assessing nonlinear measures of HRV in MDD patients so that music can be used in adjunct to medication and reduce the amount of medication as well as reduce the cardiovascular complications.

\section{Methods}

This prospective interventional study was carried out in the year 2017 at the Department of Physiology, Bangabandhu Sheikh Mujib Medical University (BSMMU), Shahbag, Dhaka to observe the effect of music therapy on CANF by assessing nonlinear measures of $\mathrm{HRV}$ in 60 newly diagnosed major depressive disorder (MDD) patients, aged 20-40 years of both sex. These patients were randomized equally into 30 patients treated with only antidepressant medication (Mirtazapine) and 30 patients received music therapy (Raga Kafi based Rabindrasangeet) in addition to antidepressant medication. For comparison 30 apparently healthy subjects were taken as control.

The patients were selected from the outpatient Department of Psychiatry, BSMMU and the controls were selected from Dhaka city dwellers. The protocol of this study was approved by the Institutional Review Board of BSMMU. All patients were studied at baseline before taking any medication/music therapy and same patients were studied after 3 months with music therapy or without music but all patients were under anti depressive medication. Similarly healthy subjects were studied at baseline and after 3 months but they were not under music therapy. All these patients were free from severe depression, 
suicidal tendency, cardiovascular disorder, respiratory disease, renal disease, diabetes mellitus, thyroid disorder and other psychiatric disease. After explaining about the study, informed written consent was taken from each subject.

After enrollment the subjects were advised to follow some instruction in the previous night of HRV test day. They were advised to finish their meal by 9:00 pm on previous day, to remain free from any type of stress, not to take sedative hypnotic medication. They were requested to take light breakfast without tea and coffee and to attend the autonomic nerve function test laboratory in the Department of Physiology, BSMMU between 8:00 am to 10:00 am on the test day. A thorough physical examinations including pulse, BP, height, weight were measured and BMI was calculated. The subject was advised to take rest for 15-20 minutes in controlled laboratory environment. During this period he was not allowed to talk, eat or drink, to perform physical or mental activity, even sleep. ECG was recorded on lead II for 5 minutes by data acquisition device Power Lab 8/35 (AD instrument, Australia). HRV recording was analyzed by Lab chart software. Patient was advised to come with a mobile phone capable of playing mp3 music. Then preselected Raga Kafi based Rabindrasangeet (Tegor's song) were uploaded in his/her mobile. Then with the help of earphone he/she was advised to listen to the songs in a comfortable position every day evening for half an hour for three consecutive months. Patient was monitored by frequent home visits and also was communicated 3-5 times per week via telephone calls. Patient was advised to come for follow up assessment after 3 months in the same department.
Data were expressed as Mean $\pm \mathrm{SE}$ and percentage. Statistical analysis was done using SPSS version 20 and Microsoft Excel 2010. Paired sample ' $t$ ' test and independent sample ' $t$ ' test were done. $p$ value of $<0.05$ was considered as statistically significant.

Result

In this study, all depressed patients were similar to healthy control by age, BMI, waist hip ratio and MUAC (Table I). At baseline, mean values of pulse rate, SBP, DBP were found significantly $(\mathrm{p}<0.001)$ higher, whereas SD1, SD2 and SD1/ SD2 were significantly $(p<0.001)$ lower in MDD patients than those of normal healthy control. In addition all these parameters were not significantly different in two groups of patients before intervention with music therapy or follow up. (Table II)

After three months follow up, MDD patients taking only antidepressant medication and not under music therapy did not show significant changes in these parameters when compared to their baseline values, whereas after three months of music therapy along with same medication, mean values of pulse rate, SBP and DBP significantly $(\mathrm{p}<0.001)$ decreased but SD1, SD2 and SD1/SD2 significantly $(p<0.001)$ increased in MDD patients (Table III). Again, post intervention values of all these parameters showed similar trends in music group compared to their non music counterparts and it was statistically significant. Furthermore, SD1,SD1/ $\mathrm{SD} 2$, pulse, SBP and DBP in music group MDD patient reached close to control value (Table IV).

Table I: Age, BMI, Waist hip ratio and MUAC ( $\mathrm{n}=85)$

\begin{tabular}{lccc}
\hline Parameters & Control $(\mathrm{n}=30)$ & Non music MDD $(\mathrm{n}=28)$ & Music MDD $(\mathrm{n}=27)$ \\
\hline Age $($ years $)$ & $27.72 \pm 0.92$ & $28.96 \pm 1.37$ & $27.58 \pm 0.30$ \\
BMI $\left(\mathrm{kg} / \mathrm{m}^{2}\right)$ & $22.72 \pm 0.29$ & $21.86 \pm 0.39$ & $21.99 \pm 0.37$ \\
W/H ratio & $0.85 \pm 0.01$ & $0.87 \pm 0.00$ & $0.86 \pm 0.01$ \\
MUAC $(\mathrm{cm})$ & $28.63 \pm 0.37$ & $27.89 \pm 0.24$ & $27.75 \pm 0.17$ \\
\hline
\end{tabular}

Data were expressed as mean \pm SE. Statistical analysis was done by independent sample $t$ test and paired sample $\mathrm{t}$ test. $\mathrm{BMI}=$ Body mass index, $\mathrm{MUAC}=\mathrm{Mid}$ upper arm circumference. $\mathrm{W} / \mathrm{H}=$ Waist hip ratio

J Bangladesh Soc Physiol. 2019, June; 14(1): 7-13 
Table II : Baseline values of nonlinear measures and pulse rate, systolic blood pressure (SBP) and diastolic blood pressure (DBP) in different groups $(\mathrm{n}=85)$

\begin{tabular}{lccc}
\hline Parameters & Control $(\mathrm{n}=30)$ & Non music MDD $(\mathrm{n}=28)$ & Music MDD $(\mathrm{n}=27)$ \\
SD1 & $24.34 \pm 1.94$ & $11.25 \pm 0.85^{* * *}$ & $11.99 \pm 1.11^{* * *}$ \\
SD2 & $49.34 \pm 1.56$ & $33.54 \pm 1.65^{* * *}$ & $34.24 \pm 1.64^{* * *}$ \\
SD1/SD2 & $0.49 \pm 0.02$ & $0.34 \pm 0.02^{* * *}$ & $0.34 \pm 0.03^{* * *}$ \\
Pulse (beats/min) & $74 \pm 1.25$ & $81.32 \pm 1.62^{* * *}$ & $82.40 \pm 1.89^{* * *}$ \\
SBP(mm of Hg) & $120.17 \pm 1.30$ & $126.61 \pm 0.75^{* * *}$ & $127.40 \pm 0.90^{* * *}$ \\
DBP(mm of Hg) & $78 \pm 0.82$ & $81.25 \pm 0.85^{* * *}$ & $82.59 \pm 0.62^{* * *}$ \\
\hline
\end{tabular}

Data were expressed as mean \pm SE. Statistical analysis was done by independent sample $t$ test and paired sample $\mathrm{t}$ test. $\mathrm{SBP}=$ Systolic blood pressure, $\mathrm{DBP}=$ Diastolic blood pressure, $\mathrm{SD} 1=$ Standard deviation of short term $\mathrm{RR}$ interval variability $\mathrm{SD} 2=$ Standard deviation of long term $\mathrm{RR}$ interval variability SD1/SD2 ratio $=$ Ratio of short term and long term RR interval variability * $=$ Control baseline vs MDD baseline.

Table III : Pre follow up values of nonlinear measures and pulse rate, systolic blood pressure (SBP) and diastolic blood pressure (DBP) in different groups $(n=85)$

\begin{tabular}{lccccc}
\hline Parameters & \multicolumn{2}{c}{ Non music MDD $(\mathrm{n}=28)$} & & \multicolumn{2}{c}{ Music MDD $(\mathrm{n}=27)$} \\
\cline { 2 - 3 } \cline { 5 - 6 } & Pre & Post & & Pre & Post \\
\hline SD1 & $11.25 \pm 0.85$ & $11.54 \pm 0.94$ & & $11.99 \pm 1.11$ & $18.54 \pm 1.16^{* * *}$ \\
SD2 & $33.54 \pm 1.65$ & $33.88 \pm 1.64$ & & $34.24 \pm 1.64$ & $40.58 \pm 2.45^{*}$ \\
SD1/SD2 & $0.34 \pm 0.02$ & $0.34 \pm 0.03$ & & $0.34 \pm 0.03$ & $0.47 \pm 0.09^{* *}$ \\
Pulse rate(beats/min) & $81.32 \pm 1.62$ & $82.64 \pm 1.51$ & & $82.40 \pm 1.89$ & $79.33 \pm 1.89^{*}$ \\
SBP(mm of Hg) & $126.61 \pm 0.75$ & $126.79 \pm 1.03$ & & $127.40 \pm 0.90$ & $121.85 \pm 1.39^{* * *}$ \\
DBP(mm of Hg) & $81.25 \pm 0.85$ & $82.85 \pm 0.75$ & & $82.59 \pm 0.62$ & $79.81 \pm 1.02^{*}$ \\
\hline
\end{tabular}

Data were expressed as mean \pm SE. Statistical analysis was done by independent sample $t$ test and paired sample $\mathrm{t}$ test. $\mathrm{SBP}=$ Systolic blood pressure, $\mathrm{DBP}=$ Diastolic blood pressure, $\mathrm{SD} 1=$ Standard deviation of short term $\mathrm{RR}$ interval variability $\mathrm{SD} 2=$ Standard deviation of long term $\mathrm{RR}$ interval variability SD1/SD2 ratio = Ratio of short term and long term $\mathrm{RR}$ interval variability. $* \mathrm{P}<0.05 * * \mathrm{p}<0.01 \quad * * * \mathrm{P}<0.001$.

Table IV : Post follow up values of nonlinear measures and pulse rate, systolic blood pressure (SBP) and diastolic blood pressure (DBP) in different groups $(\mathrm{n}=85)$

\begin{tabular}{lccc}
\hline Parameters & Control $(\mathrm{n}=30)$ & Non music MDD $(\mathrm{n}=28)$ & Music MDD $(\mathrm{n}=27)$ \\
\hline SD1 & $22.47 \pm 1.89$ & $11.54 \pm 0.97^{* * *}$ & $18.54 \pm 1.16^{\#}$ \\
SD2 & $50.69 \pm 2.68$ & $33.88 \pm 1.64^{* * *}$ & $40.58 \pm 2.45^{\#}$ \\
SD1/SD2 & $0.43 \pm 0.02$ & $0.34 \pm 0.03^{* *}$ & $0.47 \pm 0.02^{\#}$ \\
Pulse rate(beats/min) & $73 \pm 1.29$ & $82.64 \pm 1.51^{* * *}$ & $79.33 \pm 1.89$ \\
SBP(mm of Hg) & $122.67 \pm 1.30$ & $126.79 \pm 1.03$ & $121.85 \pm 1.39^{\# \#}$ \\
DBP(mm of Hg) & $80.83 \pm 0.75$ & $82.85 \pm 0.76$ & $79.81 \pm 1.02^{\#}$ \\
\hline
\end{tabular}

Data were expressed as mean \pm SE. Statistical analysis was done by independent sample $t$ test and paired sample $\mathrm{t}$ test. $\mathrm{SBP}=$ Systolic blood pressure, $\mathrm{DBP}=$ Diastolic blood pressure, $\mathrm{SD} 1=$ Standard deviation of short term $\mathrm{RR}$ interval variability $\mathrm{SD} 2=$ Standard deviation of long term $\mathrm{RR}$ interval variability SD1/SD2 ratio = Ratio of short term and long term RR interval variability * =Control post follow up vs MDD post follow up.\#= post non music MDD vs post music MDD. ${ }^{* * *} \mathrm{P}<0.001, * * \mathrm{P}<0.01, \quad \# \# \mathrm{P}<0.001 . \quad \#<0.05$ 


\section{Discussion}

In this study, significantly higher resting pulse rate, SBP and DBP in newly diagnosed MDD patients compared to control suggest subtle disorder of cardiac autonomic regulation associated with MDD. This observation agreed to other investigators except for $\mathrm{DBP}^{5,20-21}$. In contrast, some researchers found opposite result $^{22,23}$. But van der Kooy in 2007 found no significant change in DBP between depressed elderly patients and control ${ }^{24}$.

After listening to music along with medication for three months, significant decrement of these parameters when compared with non music MDD patients taking only medication obviously point towards the role of music therapy for this improvement in cardiovascular autonomic regulation in MDD patients. In case of pulse rate, similar finding was reported by other investigators and they did not report about changes in BP in MDD patients ${ }^{25}$. These results agree to others in both healthy subjects and depressed patients ${ }^{26-28}$. In 2014, Latha et al. found similar findings in case of stress ${ }^{29}$. Moreover, pulse and BP in music group of patient were close to healthy subjects which in turn strongly support the good effect of music on autonomic regulation.

In the present study lower cardiac autonomic modulation indicated by lower values of non linear measures in MDD patients compared to healthy controls agree to other researchers who observed significant decrement of SD1 and also SD2 parameter in depressed patients compared to healthy control ${ }^{30,31}$

Significantly lower baseline values of SD1, SD2 and SD1/SD2 ratio in all newly diagnosed MDD patients compared to healthy controls is suggestive of poor parasympathetic function in MDD. Again significant increment in these parameter after listening music for 3 months demonstrate the effect of music therapy on improvement of this component of autonomic function in MDD. This observation is further

J Bangladesh Soc Physiol. 2019, June; 14(1): 7-13 supported by the results of these parameters in MDD patients who were not given music therapy by continued depressed parasympathetic modulation after 3 months follow up. It was apparent that 3 months of music therapy could restore these parameters close to control value.

But several other investigators reported similar effect on SD1/SD2 by using musical instrument to produce auditory stimulus ${ }^{32,33}$. In 2015, Mukherjee et al. also find similar findings in case of Rabindra Sangeet on normal healthy individuals ${ }^{34}$.

The exact mechanism of music affecting cardiac autonomic nerve function is not well understood. Some observed physiological relaxation due to music therapy as evidenced by increase in parasympathetic activity and decrease in sympathetic activity ${ }^{34,35}$.

\section{Conclusion}

This study concludes that music therapy improved cardiac autonomic nerve function by increasing parasympathetic activity and parasympathetic dominance autonomic balance in MDD which was evidenced by significant increment of non linear measures.

Acknowledgement : This study received a research grant from University Grant Commission (UGC) of Bangladesh.

\section{References:}

1. World Health Organization. Depression and other common mental disorder: global health estimates[Internet].Geneva(Switzerland): World Health Organization,c2017[cited2017May10]. Availablefrom:http://www.who.int/mental_health/ management/depression/prevalence_global_ health_estimates/en/.

2. American Psychiatric Association. Diagnostic and Statistical manual of mental disorders (DSM-

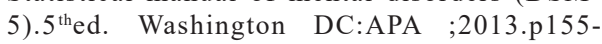
168.doi:10.1176/appibooks.97808904 25596. 295735.

3. Glassman A, Shapiro PA, Ford DE, Culpepper L, Finkel MS, Swenson JR, Bigger JT, Rollman BL, 
Wise TN. Cardiovascular health and depression. J PsychiatrPract 2003; 9(6): 409-21.

4. Nemerhoff CB, Goldschmidt-Clermont PJ. Heartache and heart break- the link between depression and cardiovascular disease. Nat Rev Cardiol 2012; 9(9):526-39.

5. Jahan CR, Begum S, Ferdousi S, Uddin MM. Impaired Cardiac Vagal Tone in Patients with Major Depressive Disorder. J Bangladesh Soc Physiol 2015; 10(2): 41-5.

6. Jahan CR, Begum S, Ferdousi S, Uddin MM. Autonomic Dysfunction in Major Depression Disorder. J Bangladesh Soc Physiol 2014; 9(1): 3741 .

7. Koschke M, Boettger MK, Schulz S, Berger S, Terhaan J, Voss A, Yeragani VK, Bar KJ. Autonomy of autonomic dysfunction in major depression. Psychosom med 2009; 71(8): 852-60.

8. Rottenberg J. Cardiac vagal control in depression: A critical analysis.Biol Psychol 2007; 74(2) : 20011.

9. Sgoifo A, Carnevelli L, Alfonso MdeLA, Amore M. Autonomic sys function and heart rate variability in depression. Stress 2015;18(3):343-52.

10. Task Force of the European Society of Cardiology and the North American Society of Pacing and Electrophysiology. Heart rate variability: standards of measurement, physiological interpretation and clinical use. Circulation 1996; 93:1043-65

11. Massaro S, Pecchia L. Heart rate variability (HRV) analysis : a methodology for organizational neuroscience. Organ Res Methods 2016; 22(1):140 .

12. Hsu C-H, Tsai M-A, Huang G-S, L T-C, Chen K-P, Ho S-T, Shyu LY, Li C-Y. Poincare plot index of heart rate variability detect dynamic autonomic modulation during general anesthesia induction. ActaAnaesthesiol Taiwan 2012;50(1) :12-18.

13. Voss A, Schulz S, Schroeder R, Baumert M, Caminal P. Methods derived from nonlinear dynamics for analyzing heart rate variability. Philos Trans A Math PhysEngSci 2009; 367(1887):277-96. doi: 10.1098/rsta.2008.0232

14. Kahloul M,Mhamdi S, NakhliMS,Sfeyhi AN, Azzaza M, Chaouch A, Naija W. Effects of music therapy under general anesthesia in patients undergoing abdominal surgery. Libyan J Med 2017;12(1): 1260886. doi:10.1080/19932820.2017.1260886.
15. Magill-Levreault L. Music therapy in pain and symptom management. J Palliat Care 1993; 9(4) : 42-8.

16. Sharma M, Rajnee and Mathur KC. Effects Of Music Therapy On Clinical And Biochemical Parameters Of Metabolic Syndrome. J Bangladesh Soc Physiol 2011;6(2): 108-15.

17. Aalbers S, Fusar-Poli L, Freeman RE, Spreen M, Ket JCF, Vink AC, Maratos A, Crawford M, Chen XJ, Gold C. Music therapy for depression. Cochrane Database Syst Rev 2017;(11) : CD004517. doi:10. 1002/14651858.CD004517.pub3.

18. Maratos AS, Gold C, Wang X, Crawford MJ. Music therapy for depression. Cochrane Database Syst Rev2008; 23(1): CD004517. doi: 10.1002/ 14651858.CD004517.pub2.

19. Gold C, Heldal TO, Dahle T, Wigram T. Music therapy for schizophrenia or schizophrenia like illnesses. Cochrane Database Sys Rev 2005; (2):CD 004025. doi:10.1002/1451858.CD 004025.pub2.

20. Schumann A, Andrack C, Bar KJ. Differences of sympathetic and parasympathetic modulation in major depression. ProgNeuropsychopharmacolBiol Psychiatry 2017;79(pt B) : 324-331. doi: 10.1016/ j.pnpbp.2017.07.009. Epub 2017 Jul 12.

21. Udupa K, Sathyaprabha TN, Thirthalli J, Kishore KR, LavekarGS, Raju TR, Gangadhar BN. Alteration of cardiac autonomic function in patients with major depression: A study using heart rate variability measures. J Affect Disord 2007; 100(1-3):137-41. doi:10.1016/j.jad.2006.10.007.

22. Agelink M W, Boz C, Ullrich $\mathrm{H}$, Andrich. Relationship between major depression and heart rate variability: Clinical consequences and implications for antidepressive treatment. Psychiatry Res 2002;113(2):139-49.

23. Moser M, Lehofer M. Hoechr-Saric R, Melod DR, Hildebrandt G, Steinbrenner B, Voiea M, Liebmann $\mathrm{P}$, Zapotoczky HG. Increased heart rate in depressed subjects inspite of unchanged autonomic balance? J Affect Disord 1998;48(2-3): 115-124.

24. Van der Kooy KG, Van Hout PJ, Van Marwijk, Haan $\mathrm{M}$, Stehouwer CDA ,Beekman ATF. Int J Ger Psychiatry 2006; 21: 147-150. doi: 10.1098/rsta. 2008.0232 .

25. Pardeshi S, Hatekar A. Comparative study of heart rate variability in major depressive disorder \& healthy individuals. Indian J Pharmacol 2017; 61(3): 256-61.

J Bangladesh Soc Physiol. 2019, June; 14(1): 7-13 
26. Suguna S, Deepika K. The effects of music on pulse rate and blood pressure in healthy young adults. Int J Res Med Sci 2017; 5(12): 5268-72. doi:10.18203/ 2320-6012.ijrms20175438.

27. Lai Y. Effects of music listening on depressed women in Taiwan. Ment Health Nurs 1999; 20(3): 229-46.

28. Hsu W-C, Lai H-L. Effects of music on major depression in psychiatric in patients. Arch PsychiatrNurs 2004; 18(5):193-99

29. Latha R. Srikanth S, Sairaman H, Dity NRE.Effect of music on heart rate variability and stress in medical students. Int. J. Clin. Exp.Physiology 2014; $1(2): 131-34$.

30. Schulz S, koschke M, Bar KJ, Voss A. The altered complexity of cardiovascular regulation in depressed patients. PhysiolMeas 2010; 31(3) : 303-24.

31. Chen X, Yang R, Kuang D, Zhang L, Lv R, Huang $\mathrm{X}, \mathrm{Wu} \mathrm{F}$, Lao $\mathrm{G}, \mathrm{Ou} \mathrm{S}$. Heart rate variability in patients with major depression during a clinical autonomic test. Psychiatry Res 2017; 256 :20711. doi: 10.1016/j.psychres.2017.06.041.
32. Roque AL, Valenti VE, Guida HL, Campos MF, Knap A,Vanderlei LCM, Ferreira LL, Ferreira C, Abreu LC. The effects of auditory stimulation with music on heart rate variability in healthy women. Clinics 2013; 68(7):960-967.doi: 10.6061/clinics/ $2013(07) 12$.

33. Roy B, Choudhury R, Pandey A, BandopadhyayS, Sararangi S, Ghatak SK. Effect of Rotating Acoustic Stimulus on Heart Rate Variability in Healthy Adults. Open Neurol J 2012; 6: 71-7. doi: 10.2174/ $1874205 \times 01206010071$.

34. Mukherjee S, Palit SK, Banerjee S, Bhattacharya DK. A comparative study on three different types of music based on same indian raga and their effects on human autonomic nervous systems, in Chaos, Complexity and Leadership, Erçetin aa, Banerjee S, editors. Cham: Springer International Publishing; 2013, p243-254. doi:10.1007/978-3-319-09710$7-21$.

35. Aldridge D. Music therapy research: A review of the medical research literature within a general context of music therapy research. Arts Psychother 1993; 20(1) :11-35. 